\title{
Effect on intraocular pressure of local anaesthesia in eyes undergoing intraocular surgery
}

\author{
E O'Donoghue, M Batterbury, T Lavy
}

\begin{abstract}
A total of 104 eyes undergoing intraocular surgery were studied to investigate the effect on intraocular pressure (IOP) of peribulbar and retrobulbar anaesthesia in eyes with and without glaucoma. Forty eyes had glaucoma. Intraocular pressure was measured before, immediately after, and 5 minutes after injection of local anaesthetic. Mean IOP rose by $5.8 \mathrm{~mm}$ $\mathrm{Hg}$ at 1 minute $(\mathrm{p}<0.01)$ and $0.7 \mathrm{~mm} \mathrm{Hg}$ at 5 minutes $(p>0.05)$. However, in eyes not receiving external ocular compression after the 1 minute measurement $(n=70,67 \%)$, IOP was still $3.6 \mathrm{~mm} \mathrm{Hg}$ higher than baseline $(p<0.01)$, compared with $5.2 \mathrm{~mm} \mathrm{Hg}$ lower than baseline $(\mathbf{p}<\mathbf{0} \cdot 01)$ where compression was used. Patients with glaucoma experienced higher and more persistent increases in IOP than those without glaucoma. The increase in IOP varied greatly between patients: the maximum rise was $25 \mathrm{~mm} \mathrm{Hg}$, and in one glaucoma patient an IOP of $50 \mathrm{~mm} \mathrm{Hg}$ occurred, persisting for 5 minutes. At 1 minute, 14 of the glaucoma subjects $(35 \%)$ had experienced an IOP rise of $\geqslant 10 \mathrm{~mm} \mathrm{Hg}$, and four $(10 \%)$ a rise of $\geqslant 20 \mathrm{~mm}$ Hg. These results suggest that the changes in IOP in patients with glaucoma, with an acute increase in IOP being succeeded by an acute decrease on entry into the anterior chamber, may be hazardous. The implications for clinical practice are discussed.

(Brf Ophthalmol 1994; 78: 605-607)
\end{abstract}

Local anaesthesia has become increasingly popular for a variety of intraocular procedures, particularly with the increasing popularity of day case surgery. The main techniques used to administer local anaesthesia are peribulbar and retrobulbar injections. However the effect of these on intraocular pressure (IOP) has received little attention in patients with glaucoma, in whom transient severe increases in IOP may have the potential to cause further compromise of visual function.

This study was initiated to examine the effect on IOP of peribulbar and retrobulbar injections, in patients with and without glaucoma, undergoing extracapsular cataract extraction or trabeculectomy. \footnotetext{
Manchester Royal Eye
Hospital

E O'Donoghue

M Batterbury

T Lavy

Correspondence to: E O'Donoghue, Manchester Royal Eye Hospital, Oxford Road, Manchester M13 9WH.

Accepted for publication 11 April 1994
}

\section{Patients and methods}

One hundred and four patients were recruited prospectively to the study. Each received either a peribulbar injection or a retrobulbar injection, of either bupivacaine $0.5 \%$ in a ratio of $50: 50$ with lignocaine $2 \%$ plus 150 units of hyaluronidase, or prilocaine $3 \%$ with felypressin plus 150 units of hyaluronidase. Intraocular pressure was measured with the Perkins applanation tonometer, immediately before injection, and at 1 and 5 minutes after injection. In a random selection of cases, owing to the preference of one particular consultant in charge of the care of some of the patients, external ocular compression in the form of the McIntyre bag of mercury was applied after the 1 minute IOP estimation until the 5 minute IOP estimation.

Data were recorded on a spreadsheet and analysed with a personal computer statistical package (Unistat for Windows). Paired and unpaired $t$ tests were used to test the null hypothesis of no difference between the means of paired or unpaired samples, and analysis of variance followed by multiple range testing for homogeneity of subsets was used to test the importance of multiple factors on IOP changes.

\section{Results}

Of the 104 patients, 38 underwent peribulbar injection, with bupivacaine/lignocaine/hyaluronidase $(\mathrm{BLH})(\mathrm{n}=16)$ or prilocaine/felypressin/ hyaluronidase $(\mathrm{PFH})(\mathrm{n}=22)$, and 66 received a retrobulbar injection ( $\mathrm{BLH} n=34, \mathrm{PFH} n=32)$. There were 40 patients with glaucoma. Seventy two patients underwent extracapsular cataract extraction with insertion of lens implant (ECCE), eight of whom had glaucoma, and 32 underwent trabeculectomy. Of the patients with glaucoma, seven had a peribulbar injection and 33 a retrobulbar injection. IOP could not be measured accurately in two subjects at 5 minutes owing to excessive tear film.

\section{EFFECT ON IOP (TABLE 1)}

In all subjects, there was a mean increase in IOP of $5.8 \mathrm{~mm} \mathrm{Hg}$ (SD $6.0,95 \%$ confidence interval $4 \cdot 6,7 \cdot 0)$ at 1 minute after injection. The mean increase in IOP at 5 minutes in those patients who did not undergo ocular compression was $3.6 \mathrm{~mm} \mathrm{Hg}$ (SD 5.9, $95 \%$ CI 2.2, 5.0), compared with baseline. In those patients who received ocular compression, there was a mean decrease in IOP of $5.2 \mathrm{~mm} \mathrm{Hg}$ (SD $5 \cdot 5,95 \% \mathrm{CI}-3 \cdot 3$, $-7 \cdot 0$ ). The maximum IOP rise was $25 \mathrm{~mm} \mathrm{Hg}$ at 1 minute and $23 \mathrm{~mm} \mathrm{Hg}$ at 5 minutes (Table $3)$.

\section{EFFECT ON IOP OF INJECTION TECHNIQUE} (TABLE 1)

Both the peribulbar and retrobulbar injection techniques produced a similar increase in IOP at 1 minute and 5 minutes. The difference between techniques was not statistically significant. The mean volume used in the peribulbar injection was $9 \mathrm{ml}$, and in retrobulbar injection $3.5 \mathrm{ml}$ $(\mathrm{p}<0.01$, unpaired $t$ test $)$ 
IOP CHANGE IN GLAUCOMA

The mean baseline IOP of the glaucoma subjects was $26 \mathrm{~mm} \mathrm{Hg}$ and that of the non-glaucoma subjects $17.5 \mathrm{~mm} \mathrm{Hg}$ (difference $8.5 \mathrm{~mm} \mathrm{Hg}$, $95 \%$ CI $6.5,10.4, \mathrm{p}<0.01)$. The IOP changes at 1 and 5 minutes were significantly higher in the glaucoma patients (Table 2). The maximum increase in IOP in the glaucoma patients was $25 \mathrm{~mm} \mathrm{Hg}$ at 1 minute and $23 \mathrm{~mm} \mathrm{Hg}$ at 5 minutes. In one subject the IOP elevated to $50 \mathrm{~mm} \mathrm{Hg}$, sustained for 5 minutes. Analysis of variance was performed to examine the importance of injection technique on these IOP changes. However injection technique was not a significant factor, whereas having glaucoma was.

Table 1 Effect of injection technique on intraocular pressure (compared with baseline) ( $\mathrm{mm} \mathrm{Hg}$ )

\begin{tabular}{llll}
\hline & & \multicolumn{2}{l}{ Subgroups } \\
\cline { 3 - 4 } & All subjects & Peribulbar & Retrobulbar \\
\hline 1 Minute: & & & \\
mean & $+5 \cdot 8^{\star}$ & $+6 \cdot 2 \ddagger$ & $+5 \cdot 6 \ddagger$ \\
SD & $6 \cdot 0$ & $5 \cdot 5$ & $6 \cdot 4$ \\
$95 \%$ CI & $4 \cdot 6,7 \cdot 0$ & $4 \cdot 4,8 \cdot 0$ & $4 \cdot 0,7 \cdot 2$ \\
n & 104 & 38 & 66 \\
5 Minutes: & & & \\
mean & $+0 \cdot 7 \dagger$ & $-0 \cdot 6 \star \star$ & $+1 \cdot 4 \star \star$ \\
SD & $7 \cdot 1$ & $5 \cdot 3$ & $7 \cdot 9$ \\
95\% CI & $-0 \cdot 7,2 \cdot 1$ & $-2 \cdot 4,1 \cdot 1$ & $-0 \cdot 5,3 \cdot 4$ \\
n & 102 & 36 & 66 \\
\hline
\end{tabular}

${ }^{\star} \mathrm{p}<0.01$ paired $t$ test, compared with baseline.

$t \mathrm{p}>0.05$ paired $t$ test, compared with baseline.

$\ddagger$ Difference between means of subgroups $0.6,95 \% \mathrm{CI}-1.8$,

$\mp$ Difference between means
$3.1, \mathrm{p}>0.05$ unpaired $t$ test.

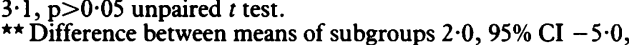
$0 \cdot 85, \mathrm{p}>0.05$ unpaired $t$ test.

Table 2 IOP changes in glaucoma $(\mathrm{mm} \mathrm{Hg})$

\begin{tabular}{|c|c|c|c|}
\hline & Non-glaucoma & Glaucoma & Difference \\
\hline $\begin{array}{l}1 \text { Minute: } \\
\text { mean } \\
\text { SD } \\
95 \% \mathrm{CI} \\
\mathrm{n} \\
\mathrm{p}\end{array}$ & $\begin{array}{l}+4 \cdot 1 \\
4 \cdot 9 \\
2 \cdot 8,5 \cdot 3 \\
64 \\
<0.01^{\star}\end{array}$ & $\begin{array}{l}+8 \cdot 6 \\
6 \cdot 6 \\
6 \cdot 5,10 \cdot 7 \\
40 \\
<0 \cdot 01^{\star}\end{array}$ & $\begin{array}{l}4 \cdot 5 \\
6 \cdot 1 \\
4 \cdot 6,7 \cdot 0 \\
- \\
<0 \cdot 01 \dagger\end{array}$ \\
\hline $\begin{array}{l}5 \text { Minutes: } \\
\text { mean } \\
\text { SD } \\
95 \% \mathrm{CI} \\
\mathrm{n} \\
\mathrm{p}\end{array}$ & $\begin{array}{l}-1 \cdot 6 \\
6 \cdot 3 \\
-3 \cdot 2,-0.02 \\
62 \\
<0.05^{\star}\end{array}$ & $\begin{array}{l}+4 \cdot 3 \\
6 \cdot 8 \\
2 \cdot 1,6 \cdot 5 \\
40 \\
<0 \cdot 01^{\star}\end{array}$ & $\begin{array}{l}5 \cdot 9 \\
7 \cdot 1 \\
3 \cdot 3,8 \cdot 5 \\
- \\
<0.01 \dagger\end{array}$ \\
\hline
\end{tabular}

* Paired $t$ test, comparing with baseline.

†Unpaired $t$ test, comparing subgroups.

Table 3 Maximal IOP increases $(\mathrm{mm} \mathrm{Hg}$ )

\begin{tabular}{clll}
\hline & $\begin{array}{l}\text { All subjects } \\
(n=104)\end{array}$ & $\begin{array}{l}\text { Non- } \\
\text { glaucoma } \\
(n=64)\end{array}$ & $\begin{array}{l}\text { Glaucoma } \\
(n=40)\end{array}$ \\
\hline $\begin{array}{c}1 \text { Minute: } \\
\text { maximum increase }\end{array}$ & 25 & 22 & 25 \\
$\begin{array}{l}\geqslant 10 \mathrm{~mm} \mathrm{Hg}(\mathrm{n}) \\
\geqslant 20 \mathrm{~mm} \mathrm{Hg}(\mathrm{n})\end{array}$ & $21(20)^{\star}$ & $7(11)$ & $14(35)$ \\
$\begin{array}{c}5 \text { Minutes: } \\
\begin{array}{c}\text { maximum increase } \\
\geqslant 10 \mathrm{~mm} \mathrm{Hg}(\mathrm{n})\end{array}\end{array}$ & 23 & 1 & 4 \\
$\geqslant 20 \mathrm{~mm} \mathrm{Hg}(\mathrm{n})$ & 3 & 20 & 23 \\
\hline
\end{tabular}

Figures in parenthesis are $\%$ of column.

Table 4 Effect of ocular compression on IOP change ( $\mathrm{mm} \mathrm{Hg}$ ) at 5 minutes (compared with baseline)

\begin{tabular}{llll}
\hline & $\begin{array}{l}\text { With } \\
\text { compression }\end{array}$ & $\begin{array}{l}\text { Without } \\
\text { compression }\end{array}$ & Difference \\
\hline Mean & $-5 \cdot 2$ & $+3 \cdot 6$ & $8 \cdot 8$ \\
SD & $5 \cdot 5$ & $5 \cdot 9$ & $5 \cdot 8$ \\
$95 \%$ CI & $-2 \cdot 6,-7 \cdot 8$ & $1 \cdot 7,5 \cdot 5$ & $6 \cdot 4,11 \cdot 2$ \\
n & 34 & 68 & - \\
p & $<0 \cdot 01^{\star}$ & $<0 \cdot 01^{\star}$ & $<0 \cdot 01 \dagger$ \\
\hline
\end{tabular}

$\star$ Paired $t$ test, comparing with baseline.

†Unpaired $t$ test, comparing subgroups.
At 1 minute, 14 of the glaucoma subjects (35\%) had experienced an IOP increase of $\geqslant 10 \mathrm{~mm} \mathrm{Hg}$, and four $(10 \%)$ an increase of $\geqslant 20 \mathrm{~mm} \mathrm{Hg}$. At 5 minutes, the numbers were 5 and 2 respectively (Table 3).

\section{OCULAR COMPRESSION}

In 34 patients, ocular compression was performed after the 1 minute IOP measurement. This reduced the tendency for the IOP still to be elevated at 5 minutes (Table 4). Only four patients with glaucoma also had ocular compression, resulting in an IOP fall of $5.2 \mathrm{~mm} \mathrm{Hg}$ compared with a rise of $5.4 \mathrm{~mm} \mathrm{Hg}$ without compression, too few for valid statistical analysis to be performed, but indicating that in these patients also the IOP rise at 5 minutes might be prevented.

\section{ANAESTHETIC AGENT}

Analysis of variance showed that the type of local anaesthetic agent used was not a factor in IOP changes.

\section{Discussion}

Previous studies have confirmed that retrobulbar and peribulbar injection of local anaesthetic can cause an elevation in intraocular pressure. Jay ${ }^{1}$ reported mean increases of $4.7 \mathrm{~mm} \mathrm{Hg}$ and $6.1 \mathrm{~mm} \mathrm{Hg}$ immediately after retrobulbar injection volumes of 3,4 , and $5 \mathrm{ml}$. IOP increases did not differ significantly between these three groups. Palay ${ }^{2}$ recorded a mean rise of $6.2 \mathrm{~mm} \mathrm{Hg}$ after a $4 \mathrm{ml}$ retrobulbar injection in 30 patients. Ropo ${ }^{3}$ recorded a rise of $25 \%$ following peribulbar injection of 7-12 $\mathrm{ml}$ of anaesthetic, at 10 minutes. Meyer ${ }^{+}$reported smaller increases of $3.4 \mathrm{~mm} \mathrm{Hg}$ and $2.9 \mathrm{~mm} \mathrm{Hg}$ with peribulbar and retrobulbar injections respectively. However the retrobulbar injections were similar in volume to the peribulbar injections $(11.5 \mathrm{ml})$. Quist ${ }^{5}$ reported a clinically insignificant decrease in IOP immediately following retrobulbar injection of $2 \mathrm{ml}$ of anaesthetic. All these studies reported a lowering of IOP compared with baseline following external ocular compression. Stevens ${ }^{6}$ reported statistically significant IOP rises (mean $4.9 \mathrm{~mm} \mathrm{Hg}$ ) immediately following peribulbar injection, but not following retrobulbar injection. Sub-Tenon injection of a similar volume to the retrobulbar injection caused a comparably insignificant IOP increase. Patients with glaucoma were excluded.

Our results show increases in IOP of $6.2 \mathrm{~mm}$ $\mathrm{Hg}$ at 1 minute after peribulbar injection and $5.6 \mathrm{~mm} \mathrm{Hg}$ after retrobulbar injection (Table 1). At 5 minutes, eyes that did not undergo compression were still $3.6 \mathrm{~mm} \mathrm{Hg}$ above baseline. There was no clinical evidence of retrobulbar haemorrhage in any patient to account for an acute IOP rise. The increase in IOP is presumably secondary to rise in orbital pressure caused by the large volumes of anaesthetic injected. One would expect that the larger volume peribulbar injection would cause a greater IOP increase than the smaller volume retrobulbar injection, as reported by Stevens. ${ }^{6}$ However, we recorded a similar IOP 
rise with both techniques (Table 1). Ropo ${ }^{7}$ has demonstrated by computer tomography that solution injected into the retrobulbar space becomes extraconal 3-8 minutes following injection, and that peribulbar injection reaches the intraconal space 2-6 minutes later. This would suggest that a smaller increase in orbital volume by retrobulbar injection can nevertheless cause a comparable increase in IOP to that associated with the larger peribulbar injection by temporary entrapment of solution within the intraconal space. However, this would also imply that the IOP increase at 5 minutes would be less following retrobulbar injection, with dissipation of the smaller volume into the extraconal tissues. We did not note this (Table 1). Thus other mechanisms may be important, such as speed of injection, interindividual variation in orbital volume and compliance, resistance of the orbital septum to orbital volume increase, and vascular effects.

Only one previous study has examined the situation in patients with glaucoma. In eight glaucoma subjects, Quist ${ }^{5}$ found a mean decrease in IOP of $2 \mathrm{~mm} \mathrm{Hg}$ immediately following a retrobulbar injection of $2 \mathrm{ml}$ of anaesthetic, and a further decrease of $8 \mathrm{~mm} \mathrm{Hg}$ after 5 minutes of compression. Our results are at variance with these. Our results show that the rise in IOP is greater in patients with glaucoma and that this increase is sustained at 5 minutes (Table 2). This effect is independent of injection technique and of local anaesthetic used. This result may reflect a failure of the normal homeostatic mechanisms to compensate for a rising intraocular pressure. In glaucoma patients, transient rises in IOP may be clinically more significant, particularly in the presence of a severely compromised optic nerve head and particularly if an acute increase is then followed by an acute decrease, on entry into the anterior chamber.

It is also important to note that individuals vary greatly in their IOP response to local anaesthesia. $\mathrm{Jay}^{2}$ reported maximum increases of $18 \mathrm{~mm} \mathrm{Hg}$ in two patients following retrobulbar injection, the IOP rising to $30 \mathrm{~mm} \mathrm{Hg}$ or more in seven of 48 patients. In our study, in all patients the maximum increase in IOP was $25 \mathrm{~mm} \mathrm{Hg}$ at 1 minute, in a patient with glaucoma. At both 1 and 5 minutes the highest IOP reached was $50 \mathrm{~mm} \mathrm{Hg}$, in a glaucoma patient. At 1 minute, an increase in IOP of $\geqslant 10 \mathrm{~mm} \mathrm{Hg}$ was recorded in $20 \%$ of all patients $(n=21)$. In six patients, this increase persisted at 5 minutes (Table 3 ). These are much larger increases in IOP than previously reported.

Large increases in IOP may be highly detrimental to certain patients. We have seen one such patient, undergoing penetrating keratoplasty for spontaneous corneal perforation associated with bullous keratopathy. The perforation had been sealed preoperatively with corneal glue and a contact lens, and was still sealed immediately before the injection. However, the peribulbar injection caused an immediate increase in IOP sufficient to result in displacement of the glue and of the contact lens with flattening of the anterior chamber.

Our results were not able to differentiate with statistical significance the effects of external ocular compression on glaucomatous and nonglaucomatous eyes, but do suggest that the 5 minute IOP increase might be preventable in both groups.

Our results have implications for the use of external ocular compression. Although the IOP 5 minutes after compression may be less than the baseline IOP (Table 4), compression cannot prevent an immediate increase in IOP. The IOP course during compression is not known. In eyes that have already suffered an acute, large increase in IOP following local anaesthetic injection, further elevation of the IOP may be significantly deleterious. Compression is likely to result in an additional, albeit temporary, hypertensive effect. McDonnell et al $^{8}$ have demonstrated that IOP may increase to levels sufficient to occlude the central retinal artery immediately following application of the Honan intraocular pressure reducer. This is more likely to occur in an eye with a starting IOP greater than $30 \mathrm{~mm} \mathrm{Hg}$. A peak IOP of $130 \mathrm{~mm} \mathrm{Hg}$ was reached on application of a Honan pressure of $30 \mathrm{~mm} \mathrm{Hg}$ to an eye with an IOP of $50 \mathrm{~mm} \mathrm{Hg}$. For this reason, we have abandoned the use of ocular compression in patients with glaucoma, and one of us administers subconjunctival anaesthetic alone. Theoretically one might expect an increased incidence of choroidal effusion and suprachoroidal haemorrhage in patients rendered firstly profoundly hypertensive and then acutely decompressed by sclerostomy. We did not observe these complications. This may be because our numbers are too small, or because we aimed to achieve a slow release of aqueous before completion of the sclerostomy in those patients in whom the IOP increase was greatest.

The results presented here indicate that IOP increases following local anaesthesia by peribulbar and retrobulbar injection may be large in any one patient. In the patient with glaucoma, the increase is likely to be larger and more prolonged, and may be high enough to compromise further optic nerve head function. We believe these results merit careful attention, and are the basis for further study. We hope to be able to record intraocular and intraorbital pressure following local anaesthetic injection, both with and without external ocular compression in eyes with and without glaucoma.

1 Jay WM, Carter H, Williams B, Green K. Effect of applying the Honan intraocular pressure reducer before cataract surgery. Am F Ophthalmol 1985; 100: 523-7.

2 Palay DA, Stulting RD. The effect of ocular compression on intraocular pressure following retrobulbar anaesthesia. Ophthalmic Surg 1990; 21: 503-7.

3 Ropo A, Ruusuvaara P, Paloheimo M, Mauuksela E-L, Nikki $\mathrm{P}$. Effect of ocular compression. (Autopressor) in intraocular pressure in periocular anaesthesia. Acta Ophthalmol (Copenh) 1990; 68: 227-9.

4 Meyer D, Hamilton RC, Loken RG, Gimbel HV. Effect of combined peribulbar and retrobulbar injection of large the intracular pressure. Can F Ophthalmol 1992; 27: 230-2.

5 Quist LH, Stapleton SS, McPherson SD. Preoperative use of the Honan intraocular pressure reducer. Am $\mathcal{F}$ Ophthalmol 1983; 95: 536-8.

6 Stevens J, Giubilei M, Lanigan L, Hykin P. Sub-Tenon, retrobulbar and peribulbar local anaesthesia: the effect upon intraocular pressure. Eur f Implant Ref Surg 1993; 5: 25-8.

7 Ropo A, Nikki P, Ruusuvaara, Kivisaari L. Comparison of Ropo A, Nikki P, Ruusuvaara, Kivisaari L. Comparison of
retrobulbar and periocular injections of lignocaine by computerised tomography. $\mathrm{Br} \mathcal{F}$ Ophthalmol 1991; 75 417-20

8 McDonnell PJ, Quigley HA, Maumenee E, Stark WJ, Hutchins GM. The Honan intraocular pressure reducer. Arch Ophthalmol 1985; 103: 422-5. 